\title{
A INFLUÊNCIA DO ESTILO DE LIDERANÇA NOS RESULTADOS EM TURNOVER: REVISÃO INTEGRATIVA
}

\author{
Mayara G. Teles \\ Graduanda de Enfermagem da Faculdade de Enfermagme da UNICAMP \\ mayaragombrade@hotmail.com
}

INTRODUÇÃO: a liderança na enfermagem impacta o ambiente de trabalho, o desempenho e a motivação dos profissionais. Os mais satisfeitos e motivados, são capazes de recompensar sua organização através de maior retenção e menor rotatividade. OBJETIVO: analisar evidências disponíveis na literatura sobre a influência do estilo de liderança no turnover. MÉTODO: Revisão integrativa da literatura, pelas etapas: 1) elaboração da questão norteadora; 2) determinação dos critérios de inclusão/exclusão; 3) definição das informações a serem extraídas e categorização dos estudos; 4) avaliação dos estudos incluídos; 5) análise dos resultados e 6) apresentação da revisão sintetizada. A questão norteadora desse estudo foi: "Os estilos de liderança do enfermeiro podem influenciar no turnouver?". Critérios de inclusão: artigos originais, disponíveis na íntegra no sistema eletrônico de periódicos das bibliotecas da Universidade Estadual de Campinas, publicados entre o período de 2012 a 2018, em inglês, português ou espanhol. As buscas foram feitas nos portais: BVS e Pubmed e nas bases: CINAHL, Embase e Scopus. Teses e dissertações, estudos piloto, artigos de revisão, relatos de caso/ experiência, cartas e editoriais foram excluídos do estudo. RESULTADOS: 12 publicações foram analisadas, todas da Pubmed. O periódico mais prevalente foi o Journal of Nursing Management (50\%) seguido por Journal of Advanced Nursing (16\%). Os países que mais pesquisaram sobre o tema foram: Canadá e Arábia Saudita. Todos os artigos foram publicados em inglês, sendo hospitais como locais de estudo, desenho quantitativo, nível de evidência quatro e publicados, predominantemente nos últimos 5 anos (66\%). Em relação ao estilo de liderança, identificou-se relação direta entre liderança abusiva e tunover, ou seja, a medida que esse estilo de liderança é exercido, aumenta o tunover; e uma correlação inversa entre as lideranças autêntica e transformacional, ou seja, a prática desses estilos, diminui o tunover. CONCLUSÃO: vislumbra-se que as lideranças autêntica e transformacional exercem relação significativa 
sobre a diminuição do turnover. Novas pesquisas, no Brasil e no mundo, avaliando outros estilos de liderança, devem ser desenvolvidas para subsidiar a escolha do melhor estilo a ser adotado pelos profissionais e instituições.

Palavras-chave: Leadership. Nursing. Personnel turnover. 